\title{
Interaction of Navigation with Minimal Access Surgery
}

\author{
Siegfried Beller \\ Surgical Clinic I, Kliniken Miltenberg-Erlenbach GmbH, Erlenbach am Main, Germany \\ Email: siegfried.beller@kmeg.de
}

Received April 10, 2012; revised April 23, 2012; accepted May 18, 2012

\begin{abstract}
Minimal access surgery (MAS) includes conventional minimally invasive laparoscopic and thoracoscopic surgery, single incision laparoscopic surgery (SILS) and natural orifice transluminal endoscopic surgery (NOTES). An end of the evolution of MAS is not foreseeable, but there are still limitations. In the most common fields of intestinal surgery (cholecystectomy, appendectomy, colo-rectal resection) limitations of MAS shook dogma for surgical strategy and procedure. Automation units and telesurgical systems try to assist the surgical action. Remaining limitations are caused by lack of tactile sense and spatial awareness. With expanding application of minimal access technique in surgery the need for navigation assistance will increase. Future expansion is basically reliant on the feasibility of navigated surgery. Navigation must respect the problems of organ shift and realise continuous localisation of the surgical target as well as spatial orientation of surgical instruments and camera view.
\end{abstract}

Keywords: Minimal Access Surgery Navigation

\section{Introduction}

MAS endeavours to minimize surgical trauma to patients with miniaturisation of the surgical access. With conventional open surgery the surgical access must allow open vision and direct mechanical access to the operation site. Surgeon must be able to see and feel the surgical target tissue. Direct access with surgical instruments must be possible. However for open surgical access damage of skin, muscles and other tissue is necessary and may sometimes cause more injury to the body than the surgical therapy itself. This may lead to more pain for patients, longer periods of bed occupancy and recovery, and an increased risk for complications.

MAS originate from endoscopic diagnostic. In 1911 Hans Jacobaeus from Stockholm established the term "laparo-thoracoscopy". He was the first who visualized the abdominal and thoracic cavity with an endoscope. Up to the mid 20th century mainly diagnostic procedures were performed and some dissections of peritoneal adhesions and liver biopsies were described [1]. In the second part of the 20th century laparoscopic technique was established mostly in gynecology procedures for adnex disease [2]. Inspection through the laparoscope was performed directly to gain insight. Visualisation was realised only for the surgeon. Outside broadcast of the picture from the body inside onto a screen allows for a more ergonomic working environment and active assistance of additional persons, as they can observe the ongoing procedure.
In general surgery the technique of MAS was established when video-assistance was introduced. Since Philippe Mouret performed the first laparoscopic cholecystectomy in 1987 this technique of laparoscopic surgical procedures increased rapidly [3]. Today, MAS surgery is a daily routine and a standard procedure in many fields of general surgery.

With further development, quality of visualisation improved dramatically. Better light sources and automation of light control allow optimal illumination of the surgical field and improved camera systems provide a better picture data acquisition and processing. Also 3D-visualisation is realised. At the same time surgical access is downsized to a $2 \mathrm{~mm}$ port diameter (needlescopic surgery) or a single port technique with access for several instruments through one port and also realised through various natural orifice of the human body [4-6].

In addition to better cosmetic results, benefit for short and middle term postoperative course are evident factors for the rapid expansion of MAS. Small incisions, often less than $1 \mathrm{~cm}$, scar healthy tissue to a lesser extent in comparison with open surgery. The advantages of this are less postoperative pain, shortened hospital stay and reduced complications. Above all, this is beneficial for the national economy [7-9].

However, for the surgeon MAS also represents surgery of limited access. And limited access surgery also means narrow visualisation, reduced surgical skill, increased stress and risk for mistakes. These limitations have pro- 
bably changed surgical strategies and procedures. Computer assisted technologies try to compensate theses drawbacks and facilitate MAS. This "active navigation" is progressively applied in all fields of surgery. In contrast passive navigation assistance is realised above all in orthopaedics, neurosurgery and interventional radiology.

In contrast to most scientific essays of MAS this review will focus the limitations of MAS and its influence on diagnostic standards, indication for surgery and mode and quality of the surgical therapy. On the basis of limitations of MAS in general, the analyses focus on cholecystectomy, appendectomy and colorectal resection to be able to point out demands and potentials of navigation assistance.

\section{Principles of MAS}

MAS is performed with special instruments introduced into a body cavity through small incisions. The cavity (abdominal, thoracic or other anatomical spaces e.g. the retroperitoneal space) is inflated with carbon dioxide to create an adequate working space. Instruments are introduced via trocars and enable gas-tight access with instruments of different diameter.

Vision is realised by the laparoscope and also introduced via trocar. The laparoscope is a longitudinal optical system of lenses transferring the picture of the surgical site to a CCD-camera at the outside end of the instrument. The laparoscope also contains optical fibres to bring light from outside to inside. More recent laparoscopes can pick up the picture at the tip of the instrument with a miniaturized camera. With this system optical emission of the picture can be omitted. Usually the captured picture is monoscopic and visualized with two dimensions with a high-resolution screen.

Instruments for MAS are special designed long thin instruments with a handle bar on one side actuating an action on the tip of the instrument.

There is need to get used to the principles of operation techniques, due to reduced tactile feedback, modified eye-hand-coordination, two-dimensional view and action inversion at the pivot point of the trocar (fulcrum-effect) (Figure 1). Increased dependency of surgical assistants (e.g. camera operator) is an additional alteration in comparison with open surgery. Due to this complete change of the surgical mode of operation special training devices have become very popular $[10,11]$.

\section{Incidence and Limitation of MAS}

In the beginnings of the evolution of MAS only selected indications were considered suitable for this new surgical technique. Today also more difficult surgical diseases and even medical emergencies can be managed with MAS; however, expansion of MAS was less rapid in di- fficult procedures. Reduced vision and capacity to act may lead to more trouble in difficult surgical cases. This means, surgeons sometimes had to learn the hard way for the benefits of MAS and the success story of MAS is discussed diverging in the surgical community. This is mainly based on two limitations: Reduced surgical capacity to act and reduced surgical cognitive ability.

\subsection{Reduced Surgical Capacity to Act}

Performance of MAS depends on an adequate working space with good vision and view. With suitable instruments surgical procedures can be performed even in a very small space, e.g. in babies; [12-14] however, performance limitations can arise, when the creation of an adequate working space can not be realised with pneumoperitoneum, for example in obstruction ileus.

Surgical action is also limited mechanically due to the insertion of instruments through a small opening. In addition most designed laparoscopic instruments have a restricted mobility of four degrees of freedom (rotation in three axis and longitudinal adjustment). Therefore not any orientation is feasible at the tip of an instrument. Together with the fulcrum-effect, this waste of surgical capacity to act leads to a drawback of the surgical action (Figures 1(b), (c)).

Automation units and telesurgery systems try to assist the surgical action. Details are focused in chapter "Impact of MAS on computer-assisted surgery".

\subsection{Reduced Surgical Cognitive Ability}

Surgical vision onto the operation field is realised with a video camera. It is an indirect and usually two-dimensional view. 3D-visualisation systems try to improve the optical perception (Figure 1(c)). Optical file generation can be achieved with two-channel video-signal systems, dual chip systems and shutter mechanism ore "insect eye"-technology. Image presentation is feasible by means of a head-mounted display, active or passive polarisation of output device and spectacles as well as an autostereoscopic screen [15-18]. Optimised surgical performance was expected, but as of now, objective data supporting this presumption is missing. Obviously surgeons can easily adapt to limitations of two dimensions and eliminate this handicap [19-21].

3D-visualisation is already integrated in telesurgery systems thus depth of immersion is enhanced. (Figure 1(d)). However, beside optical perception, tactile sense is also limited. Virtual haptic as a result of enhanced depth of immersion can not counterbalance this handicap [22]. Instrumental force feedback is affected due to airproofing of trocars and stiffness of the expanded abdominal wall. This means, surgeons do not have the same tactile perception achieved in open surgery that may allow to localise 


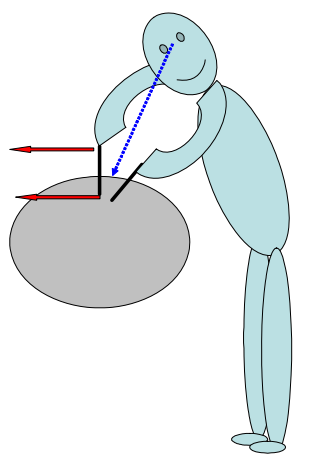

Common 3D-view

No immersion

High spatial awareness

Common tactile feedback

Normal eye-hand coordination

No inversion of movement

Normal ergonomy

(a)

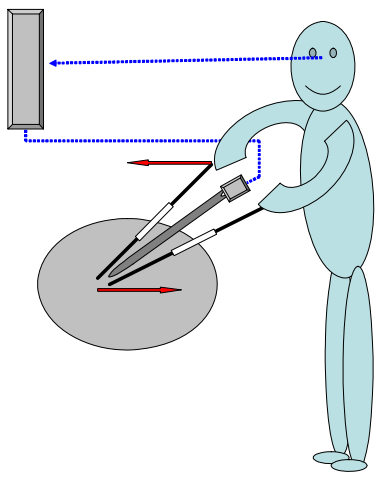

2D and 3D-view available Increasing immersion Limited spatial awareness Reduced tactile feedback

Modified eye-hand coordination

Fulcrum-effect

Bad accustomed ergonomy

(c)

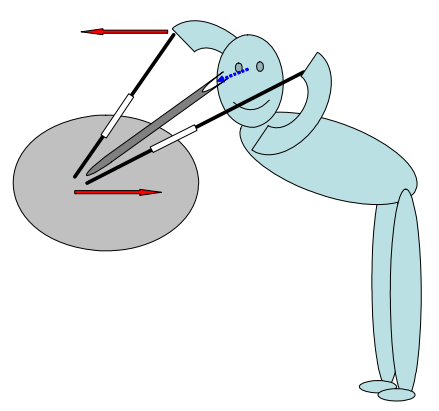

2D-view of 3D surgical space Slight immersion

Limited spatial awareness Reduced tactile feedback

Modified eye-hand coordination

Fulcrum-effect

Bad ergonomy

(b)

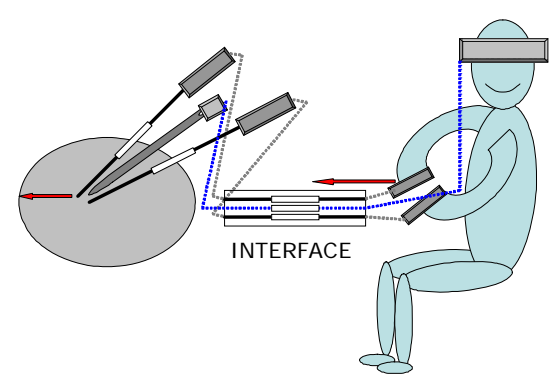

Adjustable view Deep immersion Limited spatial awareness Reduced tactile feedback Adjustable eye-hand coordination No inversion of movement Good ergonomy

(d)

Figure 1. Features of surgical work in open surgery (a); MAS with direct inspection (b); video-assisted MAS (c); and telesurgical MAS (d).

invisible tumors or vessels. Tactile perception is only rudimentary and goes missing completely in telerobotic systems. Haptic navigation and feedback systems can optimize instrumental force feedback, $[23,34]$ however tactile sense is not realised with sensor systems up to now.

In summary limits of sound application of MAS are listed in the Table $\mathbf{1}$.

\section{Influence of MAS on General Surgery Procedures}

\subsection{Surgery of Biliary Tract}

MAS is the new gold-standard for cholecystectomy. Almost all complications of gall-stones can effectively be treated with video-assisted cholecystectomy. Some authors even postulate appropriate high MAS-rates for quality management [25-28].

Ongoing disagreements exist in diagnostics and therapy necessary for patients with asymptomatic bile-duct concretions, when cholecystectomy is planned. Bile-duct concretions can be estimated with the help of liver function tests and diagnosed with ultrasound, intraoperative cholangiography and Magnetic Resonance CholangioTomography. Preoperative intravenous cholangiography and endoscopic retrograde cholangiography for diagnostic purposes are obsolete [29,30].

In the beginnings of MAS laparoscopic management of common bile-duct stones detected intraoperatively was 
Table 1. Limits of sound application of MAS.

- When available working space does not allow for efficient and safe surgical procedures due to limited visualisation or limited surgical action

- When the extent of surgical procedure exceeds operating time in such a way as to eliminate benefits of MAS

- When the result of a surgical procedure or a patient is at risk due to limited tactile or optical perception

barely conceivable. Most surgeons performed endoscopic sphincterotomy or open surgigal choledochotomy to remove bile-duct concretions. Today beside endoscopic and open surgical procedures, laparoscopic clearance of common bile-duct is feasible as well. However, the available diagnostic and therapeutic concepts have advantages and disadvantages. In literature there is still a controversy on the question of which strategy is preferable in which clinical situation.

Based on our clinical experience and investigations laparoscopic management of common bile duct concretions is preferred due to the patient-friendly strategy. Endoscopic sphinterotomy is the therapeutic strategy of choice only in severe pancreatitis and/or cholangitis [29, 31-36].

There are excellent results with laparoscopic common bile-duct clearence even in prospective randomised studies but most surgeons still favour of endoscopic splitting strategy [37]. Most surgeons are not keen to change their strategy. The results of endoscopic sphincterotomy are judged satisfying and complications of bile-duct clearence do not adhere to the surgical procedure.

Main drawbacks for primarily laparoscopic management exist when laparoscopic choledochotomy is necessary [38]. Laparoscopic choledochotomy represent a higher complication rate with probably longer hospital stay for patients. Hence great efforts should be done to reduce the rate of choledochotomy and to perform transcystic bile-duct removal more effectively [39,40]. Furthermore combination with intra- or postoperative endoscopic sphincterotomy should be considered.

\subsection{Appendectomy}

Conventional appendectomy is a typical teaching procedure in abdominal surgery. With the open access of a small laparotomy young surgeons can learn this procedure very quickly. Therefore an upgrade of this surgical training procedure to a procedure for MAS-specialists raised concerns and resistance. However, the new surgical technique established after an adequate learning period [41-43].

MAS offers diagnostic advantage in patients with minor suspicion of appendicitis and therapeutic benefit in acute inflammatory disease [44-46].

Obvious are the minimised surgical trauma of the ab- dominal wall and the reduced infection rate of the surgical access. On the other hand in open surgery sometimes an extension of laparotomy or secondary median laparotomy is necessary when inflammation of appendix is missing or in atypical location of the appendix. Above all, wound infections of the abdominal wall often are protracted.

However, most authors dispute a benefit in appendicitis when abscess, perforation or diffuse peritonitis occurs. Tendency of increased intraabdominal abscess rate is reported, [46,47] even though advantage with MAS is conceivable theoretically. Laparoscopic surgery delivers an excellent insight view to all areas of the abdominal cavity and provides well-directed efficient suction of ichor and peritoneal lavage. But there is a minimal risk in advanced peritonitis with appropriate peritoneal adhesions, when interenteric areas remain occult and insufficient exploration and lavage precludes healing of the peritonitis.

An own paper is focused on MAS versus open surgery in perforated appendicits [48]. This prospective non-randomized analysis includes extended procedures, which are sometimes necessary to manage severe complicated appendicitis. The reported "Mannheimer Peritonitis Index" indicates, that severity of peritonitis did not bias the choice of the surgical technique. In this series in $10 \%$ of patients either resection of ceacal pole or ileoceacal resection is performed. Major reason for extension of procedure and conversion are inflammatory intestinal conglomerates of appendix, ileum and colon. With laparoscopic instrumental palpation alone decision making for ileoceacal resection or appendectomy is challenging despite perfect visualisation. The complication-rate of $20 \%$ is acceptable, considering the high mean age of patients and the fact that extended procedures are included. Longlasting superficial wound infections are rare with MAS. Rates of severe intraabdominal infections are 9\% and $11 \%$ in laparoscopic ("intention to treat"-principle) and conventional open surgery.

However, some papers even prove a comparable or even reduced incidence of intraabdominal postoperative infections [49-52]. Possibly this is a reversed trend, due to the increasing experience of surgeons and an improved surgical technique. An analogue evolution was seen in laparoscopic assisted colorectal cancer surgery.

In summary advantage of MAS in appendectomy is proven in numerous studies. Good indications are atypical clinical signs, above all in females, working, fat and older patients, perforated appendicitis and retroceacal appendicitis. Drawbacks are rare injuries of bowels and bladder, higher costs for the hospital and a longer operation time during the learning phase [53,54]. Further detailed cost-benefit-analysis are necessary considering all direct and indirect costs, to define a potentially national economic benefit of this surgical technique [55-57]. 
However, open conventional appendectomy is still a good, save and contemporary surgical technique. The choice of the method should individually take account of the mentioned benefits and drawbacks.

\subsection{Colorectal Resection}

The majority of colorectal resections can be performed in minimally invasive technique. Appropriate experience of the surgical team is a prior condition to succeed. Implementation of modern surgical technology (Ultracision ${ }^{\circledR}$-, LigaSure $^{\circledR}$-technology) facilitates procedures and allows fast, bloodless and clear surgical preparation.

Several randomised studies are published and almost all prove significant better results for application of analgetics, [58-60] action of the bowels, postoperative nutrition and length of hospital stay [58-63]. Only one randomised multicenter-study found in "intention-to-treat" analysis no significant difference action of the bowels, nutrition and hospital stay [64].

Numerous randomised publications present a positive effect on immune function and surgical stress as well. [65-70] Positive effects are proved for CRP, IL-6, IL-8, IL-10, IL-1beta and CD 4/8 ratio.

Without doubt MAS can be applied in benign indications when appropriate experience is available. The location information measured from the anal verge (eg. in centimetre) may provide tremendous variations of the real topography [71]. This fact is of high significance in MAS. With MAS tumors often are more difficult to palpate and to localise. In addition, tumor localisation may probably affect the positioning of the trocars. Due to these facts some surgeons perform preoperative clip application, injection of blue dye or intraoperative coloscopy, others perform preoperative colon contrast enema, as mis-assessment of the tumor localisation may lead to misplacement of trocars [71-74].

Focussing on oncologic quality in colorectal cancer an appropriate benefit may be expected as well. Some centres of MAS could demonstrate better results for 3- and 5-year-survival after MAS of colorectal cancer in selected groups of patients, [60,63,64,67] but MAS should be elected cautious in cancer disease. Further investigations should prove acceptable results with general application of MAS in cancer disease. A clear higher rate of R1-resections in the CLASICC-trial [64] (12\% versus $6 \%$ in anterior rectum resection) may raise concerns.

In rectal cancer exact preoperative staging is self-evident and has become a gold-standard. However, due to the lack of intraoperative palpation in MAS, excessive diagnostic of localisation and local circumference is also advisable in colon cancer. During laparoscopic resection of a malignant tumor with an occult exceeding of the organ, the surgeon runs a risk to hit the tumor with the dissecting instrument, due to limited palpation.
MAS of tumours staged T4 should be judged critically and selection of patients for MAS of malignant tumours must be claimed.

Limitations of minimal access cancer surgery depend on the oncologic intention of the procedure (curative intention or palliation), the size, the circumference and localisation of the tumour and the extent of lymphatic metastases.

\section{Impact of MAS on General Surgery}

In gallstone disease most surgeons precede each laparoscopic procedure with a preoperative diagnostic of the common bile duct. This strategy enables to exclude common bile duct pathologies and allows therapeutic splitting for patients with bile duct stones if necessary. More detailed diagnostic of colorectal cancer is also advisable, when laparoscopic colorectal resection is planned. Preoperative knowledge of localisation is of higher relevance as in open surgery and the tumor stage should be identified more detailed.

Lack of tactile sense is the basic cause for an extended diagnostic specification in MAS. This is also the reason why gallstone-removal from the common bile duct is performed with the help of Dormia baskets and X-ray examination, as opposed to open surgery when stones could be removed with special instruments under palpation control. Ability to palpate is compensated with intraoperative imaging. In the same way poor ability of palpation and reduced tactile feedback is the basic cause for a high conversion rate in laparoscopic management of advanced appendicitis, when decision making for ileoceacal resection or appendectomy is challenging despite perfect visualisation.

Indication for surgery expanded since the reduced surgical access trauma provides evident advantage for the patient. Moreover MAS triggered a search for further applications of this technique and modified surgical procedures in many fields. In gastroesophageal reflux disease MAS conducted a renaissance for fundoplication and also promoted a more specific diagnostic and surgical approach $[75,76]$. MAS did not only establish for surgery of anatomical body cavities, it also extended to soft tissue. In hernia repair an evolution of "tension-free" procedures was initiated [77]. Extraperitoneal/retroperitoneal access for surgical procedures of the kidney and adrenal glands have achieved high significance [78,79]. Even total new methods were analysed e.g. in axilloscopy and dorsoposterior pelviscopy $[80,81]$.

\section{Impact of MAS on Computer-Assisted Surgery}

Action automatic units, telesurgical systems and 3Dsimulation are established in computer-assisted abdomi- 
nal MAS [82-86].

Action automatic units for camera guidance are used for colorectal surgery, [86] but routine application is reported mainly in relative easy surgical procedures (e.g. cholecystectomy and hernia surgery). The analysis of automatic units for the camera guidance indicate that the surgical camera guidance and positioning is performed intuitively by the surgeon, while the automation of the camera positioning reduces maneuvres of the camera repositioning effectively [87]. Camera guidance becomes stable and unremitting. The control mode is realised manually (direct or teleguided), acustically (with linguistic terms), with head motions or by means of colourcoded instrumental tips [88]. With assistance of the automatic camera guidance surgeons can perform various procedures alone (solo-surgery). Hence staff savings are realised [87]. But the surgeon must accept an impairment of the working comfort and a longer operating time for the benefit of staff savings. [85] Loss of camera guidance is also critically for surgical training. Besides 3D-simulation camera guidance plays a major role for the training of young surgeons [89].

The application of telesurgical systems is favourable above all in microsurgery and when required precision can not be realised with conventional MAS. Even in open surgery-e.g. in reconstruction of nerves and vessels-there often are difficult and longsome procedures, thus surgeons appreciate when telesurgical systems are applied. The master slave principle of these systems facilitate a constant concentration and smart actions over a long surgical period. Instruments of these systems offer six degrees of freedom. The external device of telesurgical systems (slave) realises four degrees with the instruments inserted through the trocar. The special designed robotic instrument offers two additional degrees of freedom realised with a wrist joint of the internal slave.

The master device of telesurgial systems is realised with a computer interface between surgeon and instruments. It can balance the fulcrum-effect easily and offers the illusion of a high depth of immersion (Figure 1(d)). Additionally the principle of these systems offer amplified potentials for simulation and training with copiloting and teleteaching [90-92].

In telesurgical systems most experience exist with DaVinci $^{\circledR}$ and Zeus ${ }^{\circledR}$ (Intuitive Surgical Inc., Mountain View, CA). DaVinci ${ }^{\circledR}$ enables to control three robotic arms. Another interactive arm carries the 3D-camera. The Zeus ${ }^{\circledR}$ system can control only two robotic arms, the third with the camera is controlled with the camera guidance system Aesop ${ }^{\circledR}$. Zeus ${ }^{\circledR}$ offers enhanced competence of telecommunication. With action scaling and tremor filtrations more ergonomic working and gain of surgical skill can be achieved [93] (Figure 1(d)).

Cardia surgery is one of the main application areas of these systems [94]. Centres of visceral surgery report application of theses systems in frequent minimally invasive procedures, as well as in technically challenging procedures [95]. In frequent technically easy procedures long machine set-up times and high costs are infavourable, while in technical challenging procedures a limited assortment of instruments is criticized [96-98].

\section{Impact of MAS on Navigated Surgery}

Navigation systems have established above all in neurosurgery, oral-maxillo-facial surgery and orthopaedics [99-103]. There is a need for navigation assistance as precise surgical dissection is required at bones and central nervous structures. In addition areas with surrounding osseous structures provide perfect topographic stability and allow firm marking and continuous position finding of land marks.

Nevertheless, due to the soft tissue of the brain and its deformability "brain-shift" is one of the major drawbacks in navigated neurosurgery, especially during dissection and resection of pathological tissue [104-106].

In internal organs of abdominal surgery navigation assistance is still in experimental stage [107-113]. Navigated surgery is reported in liver and retroperitoneal procedures [114-118]. Movement and deformability of organs are the main drawbacks as well and affect the precision of navigated surgery negatively. Due to this fact navigation support has not yet established in liver surgery and many procedures are still performed in open technique. Laparotomy allows orientation with optical and tactile sense at the same time. Direct view can be supported with intraoperative ultrasound examination and lesions can often be palpated easily.

However, there is a huge need for navigation assistance in MAS. Even in simple colon resection localisation of tumor can offer increased problems than in open surgery as described in the previous section. Without doubt application of MAS will expand in the next decade. At this time several difficult procedures are not performed routinely with MAS but published as highlights of this technique [119-123]. However, routine application is imaginable for many difficult procedures with available computer assistance for surgical manipulation as realised with telesurgical systems.

NOTES will potentially establish in various applications [4]. But exactly in this new technique straight laparoscopes and instruments will probably be replaced with flexible devices thus spatial orientation and tactile feedback is changed for the worse and application of appropriate navigation systems will be necessary [124].

In the near future MAS will probably need tools which can continuously define sterical localisation and orientation of their acting instrumental ends. Secondary it will be necessary to cope with the problems of organ shift 
during surgery and navigation in general. Especially in abdominal surgery, when dealing with mobile and soft tissue organ shift and deformity has to be recorded and respected.

\section{Conclusion}

There are multiple effects of MAS on diagnostic, indication and mode of surgical therapy in abdominal surgery. MAS challenged surgical procedures and standards and it changed existing surgical principles and conducted complete new procedures. Together with further expansion and the predicted potential of NOTES for a further revolution, a high future potential for navigation technology is supposed.

Navigation assistance could support MAS with the help of pre- and intraoperative imaging. Limitations of MAS due to reduced tactile sense could be counterbalanced with better visualisation of the surgical anatomy and spatial awareness with visualisation of surgical instruments in relation to anatomical landmarks. Basic experimental work dealing with accelerated imaging according to organ deformity during surgical procedures and information delivery to the surgeon with tools for augmented reality and navigation control will be of high future potential.

\section{REFERENCES}

[1] W. Kock, "On the Earliest History of Laparo-Thoracoscopy and the Cauterization of Adhesions," Nordisk Medicinhistorisk Årsbok, 1978, pp. 133-142.

[2] K. Semm, "Statistical Survey on Laparoscopy in Gynaecology up to 1977 in the Federal Republic of Germany," Geburtshilfe Frauenheilkd, 1979, pp. 537-544.

[3] L. Keuchel and F. Beske, "Minimally Invasive Surgery in the Federal Republic of Germany," Health Policy, Vol. 23, No. 1-2, 1993, pp. 49-65. doi:10.1016/0168-8510(93)90006-B

[4] J. Moreira-Pinto, E. Lima, J. Correia-Pinto and C. Rolanda, "Natural Orifice Transluminal Endoscopy Surgery: A Review 18," World Journal of Gastroenterology, Vol. 17, No. 33, 2011, pp. 3795-3801. doi:10.3748/wjg.v17.i33.3795

[5] H. Hu, J. Zhu, W. Wang and A. Huang, "Optimized Transumbilical Endoscopic Cholecystectomy: A Randomized Comparison of Two Procedures,” Surgical Endoscopy, Vol. 24, No. 5, 2010, pp. 1080-1084. doi:10.1007/s00464-009-0730-x

[6] O. Strobel and M. W. Buchler, "Single-Port Cholecystectomy: Is It Superior to the Conventional Laparoscopic Technique?" Chirurg, 2012.

[7] B. Jonsson and N. Zethraeus, "Costs and Benefits of Laparoscopic Surgery-A Review of the Literature," European Journal of Surgery, Vol. 166, No. S12, 2000, pp. $48-56$.
[8] W. A. Draaisma, E. Buskens, J. E. Bais, R. K. Simmermacher, H. G. Rijnhart-de Jong, I. A. Broeders and H. G. Gooszen, "Randomized Clinical Trial and Follow-Up Study of Cost-Effectiveness of Laparoscopic versus Conventional Nissen Fundoplication," British Journal of Surgery, Vol. 93, No. 6, 2006, pp. 690-697. doi:10.1002/bjs.5354

[9] K. McCormack, B. Wake, J. Perez, C. Fraser, J. Cook, E. McIntosh, L. Vale and A. Grant, "Laparoscopic Surgery for Inguinal Hernia Repair: Systematic Review of Effectiveness and Economic Evaluation," Health Technology Assessment, Vol. 9, 2005, pp. 1-4.

[10] T. Clerici, J. Lange, A. Zerz, S. Beller, G. Szinicz, U. O. Losert, H. Siegl and R. Fugger, "Educational Opportunities in Minimally Invasive Surgery," Wiener Klinische Wochenschrift, Vol. 107, 1995, pp. 43-48.

[11] G. Szinicz, S. Beller, W. Bodner, A. Zerz and K. Glaser, "Simulated Operations by Pulsatile Organ-Perfusion in Minimally Invasive Surgery,” Surgical Laparoscopy Endoscopy, Vol. 3, 1993, pp. 315-317.

[12] E. P. Nadler, K. K. Reblock, F. G. Qureshi, D. J. Hackam, B. A. Gaines and T. D. Kane, "Laparoscopic Appendectomy in Children with Perforated Appendicitis,” Journal of Laparoendoscopic \& Advanced Surgical Techniques, Vol. 16, No. 2, 2006, pp. 159-163. doi:10.1089/lap.2006.16.159

[13] Y. Suematsu and P. J. del Nido, "Robotic Pediatric Cardiac Surgery: Present and Future Perspectives," The American Journal of Surgery, Vol. 188, No. 4, 2004, pp. 98S-103S. doi:10.1016/j.amjsurg.2004.08.003

[14] O. O. Adibe, P. F. Nichol, A. W. Flake and P. Mattei, "Comparison of Outcomes after Laparoscopic and Open Pyloromyotomy at a High-Volume Pediatric Teaching Hospital,” Journal of Pediatric Surgery, Vol. 41, No. 10, 2006, pp. 1676-1678. doi:10.1016/j.jpedsurg.2006.05.051

[15] H. Liao, T. Dohi and K. Nomura, “Autostereoscopic 3D Display with Long Visualization Depth using Referential Viewing Area Based Integral Photography," IEEE Transactions on Visualization and Computer Graphics, Vol. 17, No. 11, 2011, pp. 1690-1701.

[16] H. Liao, M. Iwahara, T. Koike, N. Hata, I. Sakuma and T. Dohi, "Scalable High-Resolution Integral Videography Autostereoscopic Display with a Seamless Multiprojection System,” Applied Optics, Vol. 44, No. 3, 2005, pp. 305-315. doi:10.1364/AO.44.000305

[17] C. G. Song and J. U. Kang, "Design of the Computerized 3D Endoscopic Imaging System for Delicate Endoscopic Surgery," Journal of Medical Systems, Vol. 35, No. 1, 2011, pp. 135-141. doi:10.1007/s10916-009-9350-1

[18] A. Szold, "Seeing Is Believing: Visualization Systems in Endoscopic Surgery (Video, HDTV, Stereoscopy, and Beyond)”, Surgical Endoscopy, Vol. 19, No. 5, 2005, pp. 730-733. doi:10.1007/s00464-004-8272-8

[19] D. B. Jones, J. D. Brewer and N. J. Soper, “The Influence of Three-Dimensional Video Systems on Laparoscopic Task Performance,” Surgical Laparoscopy Endoscopy, Vol. 6, No. 3, 1996, pp. 191-197. doi:10.1097/00019509-199606000-00005 
[20] F. Tendick, S. Bhoyrul and L. W. Way, "Comparison of Laparoscopic Imaging Systems and Conditions Using a Knot-Tying Task,” Computer Aided Surgery, Vol. 2, No. 1, 1997, pp. 24-33. doi:10.3109/10929089709149080

[21] G. Crosthwaite, T. Chung, P. Dunkley, S. Shimi and A. Cuschieri, "Comparison of Direct Vision and Electronic Two- and Three-Dimensional Display Systems on Surgical Task Efficiency in Endoscopic Surgery,” British Journal of Surgery, Vol. 82, No. 6, 1995, pp. 849-851. doi:10.1002/bjs. 1800820640

[22] M. Harders, G. Bianchi, B. Knoerlein and G. Szekely, "Calibration, Registration, and Synchronization for High Precision Augmented Reality Haptics,” IEEE Transactions on Visualization and Computer Graphics, Vol. 15, No. 1, 2009, pp. 138-149. doi:10.1109/TVCG.2008.63

[23] M. Nakao, K. Imanishi, T. Kuroda and H. Oyama, "Practical Haptic Navigation with Clickable 3D Region Input Interface for Supporting Master-Slave Type Robotic Surgery," Studies in Health Technology and Informatics, Vol. 98, 2004, pp. 265-271.

[24] S. Omata, Y. Murayama and C. E. Constantinou, "MultiSensory Surgical Support System Incorporating, Tactile, Visual and Auditory Perception Modalities," Studies in Health Technology and Informatics, Vol. 111, 2005, pp. 369-371.

[25] R. Busse, U. Nimptsch and T. Mansky, "Measuring, Monitoring, and Managing Quality in Germany,s Hospitals," Health Affairs (Millwood) , Vol. 28, No. 2, 2009, pp. w294-w304. doi:10.1377/hlthaff.28.2.w294

[26] R. Kuhlen, O. Rink and J. Zacher, "Jahrbuch Qualitätsmedizin," IQM und MWC Medizinische Wissenschaftiche Verlagsgesellschaft, 2010.

[27] E. O. Turienzo-Santos, J. I. Rodriguez-Garcia, A. TrellesMartin and J. Za-Gonzalez, "Integral Management of the Process of Laparoscopic Cholecystectomy,” Cir. Esp, Vol. 80, 2006, pp. 385-394.

[28] B. P. Muller, F. Holzinger, H. Leepin and C. Klaiber, "Laparoscopic Cholecystectomy: Quality of Care and Benchmarking. Results of a Single-Institution Specialized in Laparoscopy Compared with Those of a Nationwide Study in Switzerland," Surgical Endoscopy, Vol. 17, No. 2, 2003, pp. 300-305.

[29] NIH, "NIH State-of-Science Statement on Endoscopic Retrograde Cholangiopancreaticography (ERCP) for Diagnosis and Therapy," NIH Consens State Sci Statements, 2002, pp. 1-26.

[30] S. Beller, W. Bodner, W. Kager, F. Taxer and G. Szinicz, "Gallenwegsabklärung bei Laparoskopischer Chirurgie," Minimal Invasive Chirurgie, 1992, pp. 76-78.

[31] S. Beller and G. Szinicz, "Minimally-Invasive Management of Common Bile Duct Stones," Therapeutische Umschau, Vol. 62, 2005, pp. 108-110. doi:10.1024/0040-5930.62.2.108

[32] S. Beller, W. Kager, W. Bodner, A. Zerz and G. Szinicz "Laparoskopische Cholezystektomie bei Choledocholithiasis,” Der Praktische Arzt, Jg.47/679, 1993, pp. 81-82.

[33] S. Beller, J. Rechner and G. Szinicz, "Primär Laparosko- pische Therapie der Choledocholithiasis," Langenbecks Arch. Suppl, 1994, pp. 153-155.

[34] S. Beller, W. Bodner and G. Szinicz, "Laparoskopische Therapie der Choledocholithiasis,” WiKliWo, Vol. 107, No. 2, 1995, pp. 57-60.

[35] G. Szinicz, J. Rechner and S. Beller, "Die Laparoskopische Choledochusrevision,” Foto Medico, Vol. 35, 1997, pp. 4-6.

[36] S. Beller and G. Szinicz, "Laparoskopische Gallengangssanierung-Methode der Zukunft?” Chirurgische Praxis, Vol. 65, No. 2, 2012, pp. 108-110.

[37] T. P. Huttl, C. Hrdina, T. K. Geiger, G. Meyer, F. W. Schildberg and H. J. Kramling, "Management of Common Bile Duct Stones-Results of a Nationwide Survey with Analysis of 8433 common Bile Duct Explorations in Germany," Zentralblatt fur Chirurgie, Vol. 127, 2002, pp. 282-288.

[38] Rechner, S. Beller, A. Zerz and G. Szinicz, "Double Balloon Catheter for Facilitating (Laparoscopic) Choledochus Drainage,” Der Chirurg, Vol. 67, No. 12, 1996, pp. 1266-1269. doi:10.1007/s001040050137

[39] J. Rechner, S. Beller, A. Zerz and G. Szinicz, "Laparoscopic Therapy of Choledocholithiasis," Zentralblatt fur Chirurgie, Vol. 121, 1996, pp. 278-282.

[40] S. Ebner, J. Rechner, S. Beller, K. Erhart, F. M. Riegler and G. Szinicz, "Laparoscopic Management of Common Bile Duct Stones,” Surgical Endoscopy, Vol. 18, No. 5, 2004, pp. 762-765. doi:10.1007/s00464-003-9029-5

[41] K. P. Henle, S. Beller, J. Rechner, A. Zerz, G. Szinicz and A. Klingler, "Laparoscopic versus Conventional Appendectomy: A Prospective Randomized Study," Der Chirurg, Vol. 67, 1996, pp. 526-530.

[42] A. Klingler, K. P. Henle, S. Beller, J. Rechner, A. Zerz, G. J. Wetscher and G. Szinicz, "Laparoscopic Appendectomy Does Not Change the Incidence of Postoperative Infectious Complications," American Journal of Surgery, Vol. 175, No. 3, 1998, pp. 232-235. doi:10.1016/S0002-9610(97)00286-9

[43] G. Szinicz, K. P. Henle and S. Beller, "Laparoskopische Appendektomie: Pro,” Standards in der Chirurgie, 1995, pp. 312-315.

[44] M. R. Cox, J. L. McCall, J. Toouli, R. T. Padbury, T. G. Wilson, D. A. Wattchow and M. Langcake, "Prospective Randomized Comparison of Open versus Laparoscopic Appendectomy in Men,” World Journal of Surgery, Vol. 20, No. 3, 1996, pp. 263-266. doi:10.1007/s002689900041

[45] E. Eypasch, S. Sauerland, R. Lefering and E. A. Neugebauer, "Laparoscopic versus Open Appendectomy: Between Evidence and Common Sense,” Digestive Surgery, Vol. 19, No. 6, 2002, pp. 518-522. doi:10.1159/000067608

[46] R. C. Frazee, J. W. Roberts, R. E. Symmonds, S. K. Snyder, J. C. Hendricks, R. W. Smith, M. D. Custer III and J. B. Harrison, "A Prospective Randomized Trial Comparing Open versus Laparoscopic Appendectomy," Annals of Surgery, Vol. 219, No. 6, 1994, pp. 725-728. doi:10.1097/00000658-199406000-00017 
[47] C. L. Tang, K. W. Eu, B. C. Tai, J. G. Soh, D. MacHin and F. Seow-Choen, "Randomized Clinical Trial of the Effect of Open versus Laparoscopically Assisted Colectomy on Systemic Immunity in Patients with Colorectal Cancer,” British Journal of Surgery, Vol. 88, No. 6, 2001, pp. 801-807. doi:10.1046/j.1365-2168.2001.01781.x

[48] S. Beller, J. Sturm, O. Schöneberg, T. Scherer, V. Bischof, V. Beller and G. Szinicz, "Stellenwert der Laparoskopie in der Behandlung der perforierten Appendizitis-Eine retrospektive Analyse von 142 konsekutiven Fällen,” Chirurgische Gastroenterologie, Vol. 20, No. 4, 2004, pp. 301-307. doi:10.1159/000083023

[49] R. McKinlay, S. Neeleman, R. Klein, K. Stevens, J. Greenfeld, M. Ghory and C. Cosentino, "Intraabdominal Abscess Following Open and Laparoscopic Appendectomy in the Pediatric Population," Surgical Endoscopy, Vol. 17, No. 5, 2003, pp. 730-733. doi:10.1007/s00464-002-8907-6

[50] N. Katkhouda, M. H. Friedlander, S. W. Grant, K. K. Achanta, R. Essani, P. Paik, G. Velmahos, G. Campos, R. Mason and E. Mavor, "Intraabdominal Abscess Rate after Laparoscopic Appendectomy,” The American Journal of Surgery, Vol. 180, No. 6, 2000, pp. 456-459. doi:10.1016/S0002-9610(00)00504-3

[51] G. J. Mancini, M. L. Mancini and H. S. Nelson Jr., "Efficacy of Laparoscopic Appendectomy in Appendicitis with Peritonitis,” The American Surgeon, Vol. 71, No. 1, 2005, pp. 1-4.

[52] S. Phillips, J. M. Walton, I. Chin, F. Farrokhyar, P. Fitzgerald and B. Cameron, "Ten-Year Experience with Pediatric Laparoscopic Appendectomy-Are We Getting Better?” Journal of Pediatric Surgery, Vol. 40, No. 5, 2005, pp. 842-845. doi:10.1016/j.jpedsurg.2005.01.054

[53] C. C. Cothren, E. E. Moore, J. L. Johnson, J. B. Moore, D. J. Ciesla and J. M. Burch, "Can We Afford to Do Laparoscopic Appendectomy in an Academic Hospital?” The American Journal of Surgery, Vol. 190, No. 6, 2005, pp. 950-954. doi:10.1016/j.amjsurg.2005.08.026

[54] C. Bresciani, R. O. Perez, A. Habr-Gama, C. E. Jacob, A. Ozaki, C. Batagello, I. Proscurshim and J. GamaRodrigues, "Laparoscopic versus Standard Appendectomy Outcomes and Cost Comparisons in the Private Sector," Journal of Gastrointestinal Surgery, Vol. 9, No. 8, 2005, pp. 1174-1180. doi:10.1016/j.gassur.2005.06.001

[55] R. Naf and P. Buchmann, "Is Open Appendectomy Still Up-to-Date?” Ther. Umsch, Vol. 62, 2005, pp. 111-117.

[56] D. E. Moore, T. Speroff, E. Grogan, B. Poulose and M. D. Holzman, "Cost Perspectives of Laparoscopic and Open Appendectomy," Surgical Endoscopy, Vol. 19, No. 3, 2005, pp. 374-378. doi:10.1007/s00464-004-8724-1

[57] H. Lintula, H. Kokki, K. Vanamo, H. Valtonen, M. Mattila and M. Eskelinen, "The Costs and Effects of Laparoscopic Appendectomy in Children," Archives of Pediatrics \& Adolescent Medicine, Vol. 158, 2004, pp. 34-37. doi:10.1001/archpedi.158.1.34

[58] H. Hasegawa, Y. Kabeshima, M. Watanabe, S. Yamamoto and M. Kitajima, "Randomized Controlled Trial of Laparoscopic versus Open Colectomy for Advanced Colorectal Cancer,” Surgical Endoscopy, Vol. 17, No. 4,
2003, pp. 636-640. doi:10.1007/s00464-002-8516-4

[59] W. Schwenk, B. Bohm and J. M. Muller, "Postoperative Pain and Fatigue after Laparoscopic or Conventional Colorectal Resections. A Prospective Randomized Trial,” Surgical Endoscopy, Vol. 12, No. 9, 1998, pp. 1131-1136. doi:10.1007/s004649900799

[60] R. Veldkamp, E. Kuhry, W. C. Hop, J. Jeekel, G. Kazemier, H. J. Bonjer, E. Haglind, L. Pahlman, M. A. Cuesta, S. Msika, M. Morino and A. M. Lacy, "Laparoscopic Surgery versus Open Surgery for Colon Cancer: Short-Term Outcomes of a Randomised Trial," Lancet Oncology, Vol. 6, No. 7, 2005, pp. 477-484. doi:10.1016/S1470-2045(05)70221-7

[61] K. L. Leung, S. P. Kwok, S. C. Lam, J. F. Lee, R. Y. Yiu, S. S. Ng, P. B. Lai and W. Y. Lau, "Laparoscopic Resection of Rectosigmoid Carcinoma: Prospective Randomised Trial," Lancet, Vol. 363, No. 9416, 2004, pp. 1187-1192. doi:10.1016/S0140-6736(04)15947-3

[62] M. Braga, A. Vignali, L. Gianotti, W. Zuliani, G. Radaelli, P. Gruarin, P. Dellabona and C. V. Di, "Laparoscopic versus Open Colorectal Surgery: A Randomized Trial on Short-Term Outcome,” Annals of Surgery, Vol. 236, No. 6, 2002, pp. 759-766. doi:10.1097/00000658-200212000-00008

[63] A. M. Lacy, J. C. Garcia-Valdecasas, S. Delgado, A. Castells, P. Taura, J. M. Pique and J. Visa, "LaparoscopyAssisted Colectomy versus Open Colectomy for Treatment of Non-Metastatic Colon Cancer: A Randomised Trial,” Lancet, Vol. 359, No. 9325, 2002, pp. 2224-2229. doi:10.1016/S0140-6736(02)09290-5

[64] P. J. Guillou, P. Quirke, H. Thorpe, J. Walker, D. G. Jayne, A. M. Smith, R. M. Heath and J. M. Brown, "Short-Term Endpoints of Conventional versus Laparoscopic-Assisted Surgery in Patients with Colorectal Cancer (MRC CLASICC trial): Multicentre, Randomised Controlled Trial," Lancet, Vol. 365, No. 9472, 2005, pp. 1718-1726. doi:10.1016/S0140-6736(05)66545-2

[65] S. Delgado, A. M. Lacy, X. Filella, A. Castells, J. C. Garcia-Valdecasas, J. M. Pique, D. Momblan and J. Visa, "Acute Phase Response in Laparoscopic and Open Colectomy in Colon Cancer: Randomized Study," Diseases of the Colon \& Rectum, Vol. 44, 2001, pp. 638-646. doi:10.1007/BF02234558

[66] P. M. Hewitt, S. M. Ip, S. P. Kwok, S. S. Somers, K. Li, K. L. Leung, W. Y. Lau and A. K. Li, "LaparoscopicAssisted vs. Open Surgery for Colorectal Cancer: Comparative Study of Immune Effects," Diseases of the Colon \& Rectum, Vol. 41, 1998, pp. 901-909.

doi:10.1007/BF02235376

[67] K. L. Leung, P. B. Lai, R. L. Ho, W. C. Meng, R. Y. Yiu, J. F. Lee and W. Y. Lau, "Systemic Cytokine Response after Laparoscopic-Assisted Resection of Rectosigmoid Carcinoma: A Prospective Randomized Trial," Annals of Surgery, Vol. 231, No. 4, 2000, pp. 506-511. doi:10.1097/00000658-200004000-00008

[68] W. Schwenk, "Randomized Clinical Trial of the Effect of Open versus Laproscopically Assisted Colectomy on Systemic Immunity in Patients with Colorectal Cancer," British Journal of Surgery, Vol. 89, No. 4, 2002, pp. 497. 
doi:10.1046/j.1365-2168.2002.208821.x

[69] E. M. Targarona, E. Gracia, J. Garriga, C. Martinez-Bru, M. Cortes, R. Boluda, L. Lerma and M. Trias, "Prospective Randomized Trial Comparing Conventional Laparoscopic Colectomy with Hand-Assisted Laparoscopic Colectomy: Applicability, Immediate Clinical Outcome, Inflammatory Response, and Cost," Surgical Endoscopy, Vol. 16, No. 2, 2002, pp. 234-239. doi:10.1007/s00464-001-8168-9

[70] F. P. Wu, K. Hoekman, C. Sietses, B. M.von Blomberg, S. Meijer, H. J. Bonjer and M. A. Cuesta, "Systemic and Peritoneal Angiogenic Response after Laparoscopic or Conventional Colon Resection in Cancer Patients: A Prospective, Randomized Trial,” Diseases of the Colon \& Rectum, Vol. 47, 2004, pp. 1670-1674. doi:10.1007/s10350-004-0660-6

[71] P. J. Conaghan, C. A. Maxwell-Armstrong, M. V. Garrioch, L. Hong and A. G. Acheson, "Leaving a Mark: The Frequency and Accuracy of Tattooing Prior to Laparoscopic Colorectal Surgery," Colorectal Disease, Vol. 13, No. 10, 2011, pp. 1184-1187. doi:10.1111/j.1463-1318.2010.02423.x

[72] D. L. Feingold, T. Addona, K. A. Forde, T. D. Arnell, J. J. Carter, E. H. Huang and R. L. Whelan, "Safety and Reliability of Tattooing Colorectal Neoplasms Prior to Laparoscopic Resection," Journal of Gastrointestinal Surgery, Vol. 8, No. 5, 2004, pp. 543-546. doi:10.1016/j.gassur.2003.12.016

[73] S. H. Kim, J. W. Milsom, J. M. Church, K. A. Ludwig, A. Garcia-Ruiz, J. Okuda and V. W. Fazio, "Perioperative Tumor Localization for Laparoscopic Colorectal Surgery,” Surgical Endoscopy, Vol. 11, No. 10, 1997, pp. 1013-1016. doi:10.1007/s004649900514

[74] M. Montorsi, E. Opocher, R. Santambrogio, P. Bianchi, C. Faranda, P. Arcidiacono, G. R. Passoni and F. Cosentino, "Original Technique for Small Colorectal Tumor Localization during Laparoscopic Surgery," Diseases of the Colon \& Rectum, Vol. 42, 1999, pp. 819-822. doi:10.1007/BF02236943

[75] C. W. Cartlidge, G. D. Stewart, A. C. de Beaux and S. Paterson-Brown, "The Evolution of Laparoscopic Antireflux Surgery and Its Influence on Postoperative Stay," Scottish Medical Journal, Vol. 56, No. 2, 2011, pp. 64-68. doi:10.1258/smj.2010.010014

[76] F. M. Riegler, J. Lenglinger and E. P. Cosentini, "Randomized Clinical Trial of Laparoscopic versus Open Fundoplication for Gastro-Oesophageal Reflux Disease (Br J Surg 2004; 91: 975-982)," British Journal of Surgery, Vol. 91, No. 10, 2004, p. 1381. doi:10.1002/bjs.4826

[77] E. Pelissier, A. Fingerhut and P. Ngo, "Inguinal Hernia. What Techniques Are Available for the Surgeon? Theoretical and Practical Advantages and Disadvantages,” Journal de Chirurgie (Paris), Vol. 144, Special No. 4, 2007, pp. 5S35-5S40.

[78] T. Gurtler and M. Weber, "Current Operative Techniques and Strategies in Endocrine Surgery,” Ther. Umsch, Vol. 68, 2011, pp. 279-283.

[79] J. B. Ogilvie and Q. Y. Duh, "New Approaches to the
Minimally Invasive Treatment of Adrenal Lesions," Cancer Journal, Vol. 11, No. 1, 2005, pp. 64-72. doi:10.1097/00130404-200501000-00010

[80] J. L. Brun, E. Rousseau, G. Belleannee and M. A. De G. Brun, "Axillary Lymphadenectomy Prepared by Fat and Lymph Node Suction in Breast Cancer," European Journal of Surgical Oncology, Vol. 24, No. 1, 1998, pp. 17-20. doi:10.1016/S0748-7983(98)80118-2

[81] A. Zerz, J. Beck and G. Szinicz, "Dorso-Posterior Extraperitoneal Pelviscopy (DEP). From Experiment to Initial Clinical Application,” Der Chirurg, Vol. 70, No. 3, 1999, pp. 294-297. doi:10.1007/s001040050646

[82] H. Lang, A. Radtke, M. Hindennach, T. Schroeder, N. R. Fruhauf, M. Malago, H. Bourquain, H. O. Peitgen, K. J. Oldhafer and C. E. Broelsch, "Impact of Virtual Tumor Resection and Computer-Assisted Risk Analysis on Operation Planning and Intraoperative Strategy in Major Hepatic Resection,” Archives of Surgery, Vol. 140, No. 4, 2005, pp. 629-638. doi:10.1001/archsurg.140.7.629

[83] J. Marescaux, J. M. Clement, V. Tassetti, C. Koehl, S. Cotin, Y. Russier, D. Mutter, H. Delingette and N. Ayache, "Virtual Reality Applied to Hepatic Surgery Simulation: The Next Revolution," Annals of Surgery, Vol. 228, No. 5, 1998, pp. 627-634. doi:10.1097/00000658-199811000-00001

[84] R. Marvik, T. Lango, G. A. Tangen, J. O. Andersen, J. H. Kaspersen, B. Ystgaard, E. Sjolie, R. Fougner, H. E. Fjosne and T. A. Nagelhus Hernes, "Laparoscopic Navigation Pointer for Three-Dimensional Image-Guided Surgery,” Surgical Endoscopy, Vol. 18, No. 8, 2004, pp. 1242-1248. doi:10.1007/s00464-003-9190-x

[85] B. M. Kraft, C. Jager, K. Kraft, B. J. Leibl and R. Bittner, "The AESOP Robot System in Laparoscopic Surgery: Increased Risk or Advantage for Surgeon and Patient?" Surgical Endoscopy, Vol. 18, No. 8, 2004, pp. 1216-1223. doi:10.1007/s00464-003-9200-Z

[86] U. Hildebrandt, T. Plusczyk, K. Kessler and M. D. Menger, "Single-Surgeon Surgery in Laparoscopic Colonic Resection,” Diseases of the Colon \& Rectum, Vol. 46, No. 12, 2003, pp. 1640-1645. doi:10.1007/BF02660769

[87] J. E. Jaspers, P. Breedveld, J. L. Herder and C. A. Grimbergen, "Camera and Instrument Holders and Their Clinical Value in Minimally Invasive Surgery," Surgical Laparoscopy Endoscopy \& Percutaneous Techniques, Vol. 14, No. 3, 2004, pp. 145-152. doi:10.1097/01.sle.0000129395.42501.5d

[88] K. Omote, H. Feussner, A. Ungeheuer, K. Arbter, G. Q. Wei, J. R. Siewert and G. Hirzinger, "Self-Guided Robotic Camera Control for Laparoscopic Surgery Compared with Human Camera Control,” American Journal of Surgery, Vol. 177, No. 4, 1999, pp. 321-324. doi:10.1016/S0002-9610(99)00055-0

[89] A. Zhang, M. Hunerbein, Y. Dai, P. M. Schlag and S. Beller, "Construct Validity Testing of a Laparoscopic Surgery Simulator (Lap Mentor): Evaluation of Surgical Skill with a Virtual Laparoscopic Training Simulator," Surgical Endoscopy, Vol. 22, No. 6, 2008, pp. 1440-1444. doi:10.1007/s00464-007-9625-X 
[90] W. R. Chitwood Jr., L. W. Nifong, W. H. Chapman, J. E. Felger, B. M. Bailey, T. Ballint, K. G. Mendleson, V. B. Kim, J. A. Young and R. A. Albrecht, "Robotic Surgical Training in an Academic Institution,” Annals of Surgery, Vol. 234, No. 4, 2001, pp. 475-484. doi:10.1097/00000658-200110000-00007

[91] G. Niemeyer, K. J. Kuchenbecker, R. Bonneau, P. Mitra, A. M. Reid, J. Fiene and G. Weldon, "THUMP: An Immersive Haptic Console for Surgical Simulation and Training," Studies in Health Technology and Informatics, Vol. 98, 2004, pp. 272-274.

[92] G. Graschew, T. A. Roelofs, S. Rakowsky and P. M. Schlag, "Interactive Telemedicine as a Tool to Avoid a Digital Divide in the World," Studies in Health Technology and Informatics, Vol. 103, 2004, pp. 150-156.

[93] K. Moorthy, Y. Munz, A. Dosis, J. Hernandez, S. Martin, F. Bello, T. Rockall and A. Darzi, "Dexterity Enhancement with Robotic Surgery," Surgical Endoscopy, Vol. 18, No. 5, 2004, pp. 790-795. doi:10.1007/s00464-003-8922-2

[94] J. Bonatti, T. Schachner, N. Bonaros, A. Oehlinger, M. Danzmayr, E. Rutzler, O. Bernecker, J. Margreiter, C. Velik-Salchner, G. Friedrich, P. Jonetzko and G. Laufer, "Ongoing Procedure Development in Robotically Assisted Totally Endoscopic Coronary Artery Bypass Grafting (TECAB)," Heart Surgery Forum, Vol. 8, No. 4, 2005, pp. E287-E291. doi:10.1532/HSF98.20051126

[95] G. Jacobsen, F. Elli and S. Horgan, "Robotic Surgery Update,” Surgical Endoscopy, Vol. 18, No. 8, 2004, pp. 1186-1191. doi:10.1007/s00464-003-8281-z

[96] S. Beller, M. Hünerbein and P. Schlag, "Robotik in der Viszeralchirurgie,” Jahrbücher zur Medizin-Chirurgie, 2005, pp. 39-54.

[97] S. Beller, M. Hünerbein and P. Schlag, "Computer-Und Roboter-Assistierte Viszeralchirurgie-Status quo und Perspektiven,” Viszeralchirurgie, 2006, pp. 145-152. doi:10.1055/s-2006-933431

[98] S. Beller, "Recent Significance of Mechatronic Support Systems in General Surgery," Workshop für Medizinische Robotik, Navigation und Visualisierung-Remagener Physiktage, 2007.

[99] M. Cartellieri, J. Kremser and F. Vorbeck, "Comparison of Different 3D Navigation Systems by a Clinical User," European Archives of Otorhinolaryngology, Vol. 258, 2001, pp. 38-41. doi:10.1007/s004050000302

[100] F. Gebhard, A. Weidner, U. C. Liener, U. Stockle and M. Arand, "Navigation at the spine," Injury, Vol. 35, Suppl. 1, 2004, p. S45. doi:10.1016/j.injury.2004.05.009

[101] P. Grunert, K. Darabi, J. Espinosa and R. Filippi, “Computer-Aided Navigation in Neurosurgery,” Neurosurgical Review, Vol. 26, No. 2, 2003, pp. 73-99. doi:10.1007/s10143-003-0262-0

[102] R. Seeberger, G. Kane, J. Hoffmann and G. Eggers, "Accuracy Assessment for Navigated Maxillo-Facial Surgery Using an Electromagnetic Tracking Device," Journal of Cranio-Maxillofacial Surgery, Vol. 40, 2012, pp. 156-161. doi:10.1016/j.jcms.2011.03.003

[103] M. J. Tormenti, D. B. Kostov, P. A. Gardner, A. S.
Kanter, R. M. Spiro and D. O. Okonkwo, "Intraoperative Computed Tomography Image-Guided Navigation for Posterior Thoracolumbar Spinal Instrumentation in Spinal Deformity Surgery,” Neurosurgical Focus, Vol. 28, 2010, p. E11. doi:10.3171/2010.1.FOCUS09275

[104] P. W. Willems, J. W. van der Sprenkel, C. A. Tulleken, M. A. Viergever and M. J. Taphoorn, "Neuronavigation and Surgery of Intracerebral Tumours," Journal of Neurology, Vol. 253, No. 9, 2006, pp. 1123-1136. doi:10.1007/s00415-006-0158-3

[105] C. Trantakis, M. Tittgemeyer, J. P. Schneider, D. Lindner, D. Winkler, G. Strauss and J. Meixensberger, "Investigation of Time-Dependency of Intracranial Brain Shift and Its Relation to the Extent of Tumor Removal Using Intra-Operative MRI,” Neurological Research, Vol. 25, No. 1, 2003, pp. 9-12. doi:10.1179/016164103101200923

[106] M. M. Bonsanto, A. Staubert, C. R. Wirtz, V. Tronnier and S. Kunze, "Initial Experience with an UltrasoundIntegrated Single-RACK Neuronavigation System,” Acta Neurochirurgica (Wien.), Vol. 143, No. 11, 2001, pp. 1127-1132. doi:10.1007/s007010100003

[107] K. Gavaghan, T. Oliveira-Santos, M. Peterhans, M. Reyes, H. Kim, S. Anderegg and S. Weber, "Evaluation of a Portable Image Overlay Projector for the Visualisation of Surgical Navigation Data: Phantom Studies," International Journal of Computer Assisted Radiology and Surgery, 2011. doi:10.1007/s11548-011-0660-7

[108] J. Schwaiger, M. Markert, N. Shevchenko and T. C. Lueth, "The Effects of Real-Time Image Navigation in Operative Liver Surgery,” International Journal of Computer Assisted Radiology and Surgery, Vol. 6, 2011, pp. 785-796. doi:10.1007/s11548-011-0557-5

[109] F. Volonte, F. Pugin, P. Bucher, M. Sugimoto, O. Ratib and P. Morel, “Augmented Reality and Image Overlay Navigation with OsiriX in Laparoscopic and Robotic Surgery: Not Only a Matter of Fashion," Journal of Hepato-Biliary-Pancreatic Sciences, Vol. 18, No. 4, 2011, pp. 506-509. doi:10.1007/s00534-011-0385-6

[110] S. S. Chopra, M. Hunerbein, S. Eulenstein, T. Lange, P. M. Schlag and S. Beller, "Development and Validation of a Three Dimensional Ultrasound Based Navigation System for Tumor Resection,” European Journal of Surgical Oncology, Vol. 34, No. 4, 2008, pp. 456-461. doi:10.1016/j.ejso.2007.07.011

[111] T. Lange, M. Hunerbein, S. Eulenstein, S. Beller and P. M. Schlag, "Development of Navigation Systems for Image-Guided Laparoscopic Tumor Resections in Liver Surgery," Recent Results in Cancer Research, Vol. 167, 2006, pp. 13-36. doi:10.1007/3-540-28137-1_2

[112] R. Marvik, T. Lango, G. A. Tangen, F. Lindseth, Y. Yavuz and T. A. Nagelhus Hernes, "Image-Guided Laparoscopic Surgery. Review and Current Status,” Minerva Chirurgica, Vol. 60, No. 5, 2005, pp. 305-325.

[113] R. Marvik, T. Lango, G. A. Tangen, J. O. Andersen, J. H. Kaspersen, B. Ystgaard, E. Sjolie, R. Fougner, H. E. Fjosne and T. A. Nagelhus Hernes, "Laparoscopic Navigation Pointer for Three-Dimensional Image-Guided Surgery," Surgical Endoscopy, Vol. 18, No. 8, 2004, pp. 1242-1248. doi:10.1007/s00464-003-9190-X 
[114] M. Peterhans, B. A. vom, B. Dagon, D. Inderbitzin, C. Baur, D. Candinas and S.Weber, "A Navigation System for Open Liver Surgery: Design, Workflow and First Clinical Applications,” International Journal of Medical Robotics, Vol. 7, 2011, pp. 7-16. doi:10.1002/rcs.360

[115] S. Beller, S. Eulenstein, T. Lange, M. Hunerbein and P. M. Schlag, "Upgrade of an Optical Navigation System with a Permanent Electromagnetic Position Control: A First Step towards 'Navigated Control' for Liver Surgery," Journal of Hepato-Biliary-Pancreatic Surgery, Vol. 16, No. 2, 2009, pp. 165-170. doi:10.1007/s00534-008-0040-z

[116] S. Beller, M. Hunerbein, S. Eulenstein, T. Lange and P. M. Schlag, "Feasibility of Navigated Resection of Liver Tumors Using Multiplanar Visualization of Intraoperative 3-Dimensional Ultrasound Data," Annals of Surgery, Vol. 246, No. 2, 2007, pp. 288-294. doi:10.1097/01.sla.0000264233.48306.99

[117] S. Beller, M. Hunerbein, T. Lange, S. Eulenstein, B. Gebauer and P. M. Schlag, "Image-Guided Surgery of Liver Metastases by Three-Dimensional UltrasoundBased Optoelectronic Navigation," British Journal of Surgery, Vol. 94, No. 7, 2007, pp. 866-875. doi:10.1002/bjs.5712

[118] T. Lango, G. A. Tangen, R. Marvik, B. Ystgaard, Y. Yavuz, J. H. Kaspersen, O. V. Solberg and T. A. Hernes, "Navigation in Laparoscopy-Prototype Research Platform for Improved Image-Guided Surgery,” Minimally Invasive Therapy \& Allied Technologies, Vol. 17, No. 1,
2008, pp. 17-33. doi:10.1080/13645700701797879

[119] B. Edwin, A. Nordin and A. M. Kazaryan, "Laparoscopic Liver Surgery: New Frontiers,” Scandinavian Journal of Surgery, Vol. 100, 2011, pp. 54-65.

[120] G. S. Shetty, Y. K. You, H. J. Choi, G. H. Na, T. H. Hong and D. G. Kim, "Extending the Limitations of Liver Surgery: Outcomes of Initial Human Experience in a High-Volume Center Performing Single-Port Laparoscopic Liver Resection for Hepatocellular Carcinoma," Surgical Endoscopy, 2012 (Epub. 2011).

[121] H. J. Zeh, A. H. Zureikat, A. Secrest, M. Dauoudi, D. Bartlett and A. J. Moser, "Outcomes after Robot-Assisted Pancreaticoduodenectomy for Periampullary Lesions," Annals of Surgery Oncology, 2012 (Epub. 2011).

[122] J. O. Wee and C. R. Morse, “2011 Minimally Invasive Thoracic Surgery Summit: Minimally Invasive Ivor Lewis Esophagectomy,” Journal of Thoracic and Cardiovascular Surgery, 2012 (Epub 2011).

[123] K. Maas, S. Biere, P. D. An der and M. Cuesta, "Minimally Invasive Esophagectomy: Current Status and Future Direction,” Surgical Endoscopy, 2012 (Epub 2011).

[124] V. Karimyan, F. Orihuela-Espina, D. R. Leff, J. Clark, M. Sodergren, A. Darzi and G. Z. Yang, "Spatial Awareness in Natural Orifice Transluminal Endoscopic Surgery (NOTES) Navigation,” International Journal of Surgery, 2012 (Epub 2011). 